\title{
Penguatan literasi budaya dan kewargaan berbasis sekolah di sekolah menengah pertama
}

\section{Dwi Arum Sari; Supriyadi}

Universitas Ahmad Dahlan, Yogyakarta, Indonesia

\section{INFORMASI ARTIKEL \\ Sejarah Artikel: \\ Diterima: $8 / 1 / 2021$ \\ Disetujui: $2 / 3 / 2021$ \\ Kata kunci: \\ Gerakan Litrerasi Sekolah; Penguatan; \\ Literasi Budaya dan \\ Kewarganegaraan}

\section{Keywords:}

Movement for School Literacy; Strengthening;

Cultural Literacy and Citizenship

\begin{abstract}
ABSTRAK
Gerakan literasi sekolah sangat diperlukan oleh pemangku kepentingan di dunia pendidikan utamanya peserta didik, kemampuan berliterasi peserta didik berkaitan erat dengan tuntutan keterampilan membaca yang berujung pada kemampuan memahami informasi secara analitis, kritis, dan reflektif. Tujuan penelitian ini adalah untuk mengetahui penguatan literasi budaya dan kewargaan pada siswa berbasis sekolah untuk siswa Sekolah Menengah Pertama Swasta di Kota Yogyakarta. Metode pengumpulan data yang digunakan dalam penelitian ini adalah menggunakan observasi, wawancara dan dokumentasi. Langkah penelitian yang digunakan dalam analisis data adalah menggunakan reduksi data, penyajian data dan penarikan kesimpulan. Hasil penelitian menunjukkan bahwa penguatan literasi budaya dan kewargaan kepada siswa berbasis literasi di Sekolah Menengah Pertama mampu memahamkan siswa dalam kaitannya gerakan literasi budaya dan kewargaan di sekolah yaitu adanya pelaksanaan pembiasaan membaca 15 menit sebelum pembelajaran dimulai. Adanya interaksi antara petugas perpustakaan dengan siswa, penanaman nilai-nilai karakter yang di antaranya adalah nilai karakter disiplin, kreatif, rasa ingin tahu, menghargai prestasi, mencintai budaya sendiri, gemar membaca dan tanggung jawab, pengembangan fasilitas literasi sekolah serta tingkat keterlibatan pelaku atau tim fasilitator dalam rangka penguatan literasi budaya dan kewargaan. Penelitian ini dapat digunakan sebagai acuan program penguatan literasi dan kewarganegaraan di sekolah-sekolah.
\end{abstract}

\section{ABSTRACT}

Strengthening of Cultural Literation and Citizenship School Based in Junior High School. School literacy movement is very significant for education stakeholders, especially for students. literacy is related to reading skill which enables the students to understand, analyse, criticise and reflect information. The objective of this study is to find out the culture and citizenship literacy of students of a private junior high school in Yogyakarta. The data collecting technique used in this study included observation, interview and documentation. the data processing covered data reduction, data presentation and conclusion drawing. The findings showed that strengthening culture and citizenship literacy was implemented through allowing 15 minute time to read before the first lesson started. There was also interaction between students and librarians, and character values such as discipline, creativity, curiosity, appreciation, love towards own culture, responsibility, reading interest, development of literacy facility, and the involvement of facilitator team in strengthening culture and citizenship literacy. This study can be used as a reference of strengthening citizenship and literacy program in other schools.

\section{Pendahuluan}

Gerakan literasi sekolah sangat diperlukan dalam di dunia pendidikan utamanya peserta didik, kemampuan berliterasi peserta didik sangat berkaitan erat dengan tuntutan dalam keterampilan membaca yang berujung pada kemampuan dalam memahami informasi secara kognitif, kritis, dan reflektif (Widyoko \& Muhardjito, 2018). Akan tetapi, tuntutan keterampilan pendidikan yang harus dikuasai oleh pembelajaran di sekolah yang belum mampu menumbuhkan keterampilan atau kompetensi yang dibutuhkan siswa menjadikan dasar utama bahwa literasi harus dikembangkan terutama dalam keterampilan membaca (Nahdi \& Yunitasari, 2019). Gerakan literasi sekolah saat ini belum terimplementasi dengan baik contohnya minat baca siswa yang masih rendah (Zakirman,

Korespondensi: Dwi Arum Sari, dwiarumsari25@gmail.com, Universitas Ahmad Dahlan, Yogyakarta, Indonesia 
2019). Oleh karena itu minat baca yang menduduki posisi penting bagi kemajuan suatu bangsa. dibanding dengan Negara-negara yang tergabung dalam ASEAN dan negara asing lainnya, Indonesia masih menduduki urutan terbawah dalam hal minat baca. Di tingkat Internasional, Indonesia memiliki indeks membaca 0,001 . Hal itu berarti dalam setiap seribu orang, hanya satu orang yang memiliki minat baca tinggi (Fauziyah, 2019).

Literasi budaya merupakan kemampuan dalam memahami dan bersikap terhadap kebudayaan Indonesia sebagai identitas bangsa (Desyandari, 2018). Kemampuan untuk memahami keberagaman dan tanggung jawab sebagai warga negara dari suatu bangsa merupakan kecakapan yang harus dimiliki setiap individu di era modernisasi, oleh karena itu, literasi budaya penting diberikan di sekolah, literasi budaya tidak hanya menyelamatkan dan mengembangkan budaya lokal dan nasional, tetapi juga membangun identitas bangsa Indonesia ditengah masyarakat, agar tetap mencintai dan bisa melestarikan kebudayaan berliterasi (Pratiwi \& Asyarotin, 2019). Dalam realitasnya, kemampuan dalam memahami dan bersikap terhadap kebudayaan Indonesia sebagai identitas bangsa masih lemah. Kemajuan teknologi membuat siswa melupakan referensi sejarah, mereka lebih berbasis ke barat dengan slogan globalisasi. Nilai-nilai budaya bangsa yang mendasari sikap nasionalisme digeser dengan sikap mencintai budaya barat. Akibatnya, nilai-nilai budaya sebagai perekat persatuan segenap bangsa pada generasi muda khususnya siswa memudar dan mengurangi kepedulian terhadap latar belakang sosial budaya yang ada (Frans, 2017).

Sesuai pasal 28 I ayat 3 UUD 1945, salah satu hak dan tanggung jawab warga negara adalah mengembangkan atau melestarikan identitas bangsa (Maimun et al., 2020). Dalam realitasnya, arus globalisasi telah mempengaruhi eksistensi multikulturalisme yang ada di Indonesia. Krisis yang terjadi akhir-akhir ini di Indonesia dapat dipahami sebagai akibat dari rendahnya pengetahuan kewarganegaraan pada diri masyarakat Indonesia (Maimun et al., 2020). Hal ini dikarenakan ketidaksadaran dan ketidakpahaman anak-anak Indonesia terhadap hak dan tanggung jawabnya akibat perubahan kebiasaan masyarakat atau pergeseran budaya akibat mencontoh budaya barat (Yusuf \& Putra, 2019).

Perpustakaan dilingkungan sekolah memiliki peranan penting dalam mendorong siswa agar dapat belajar secara mandiri, efektif dan sepanjang hayat.. Salah satu hasil penelitian literasi di tingkat internasional menyimpulkan dalam sebuah kalimat, "menemukan cara untuk mengajak siswa membaca merupakan suatu jalan yang sangat efektif untuk perubahan sosial". Pernyataan tersebut secara sederhana dapat kita pahami bahwa kunci keberhasilan perubahan sosial yakni melalui aktifitas membaca dan membaca sesungguhnya adalah merupakan proses belajar itu sendiri (Afifah et al., 2020).

Permasalahan pada saat ini peran perpustakaan dalam kegiatan literasi membaca masih dianggap belum maksimal, contohnya seperti buku-buku penunjang bertemakan kebudayaan dan kewargaan di perpustakaan sekolah yang diteliti masih kurang dan belum tersedianya sarana pojok baca perpustakaan dan dalam kelas. Oleh karena itu, penelitian ini bertujuan untuk melakukan evaluasi keberhasilan program penguatan literasi budaya dan kewargaan pada siswa berbasis sekolah di sebuah Sekolah Menengah Pertama Swasta di Kota Yogyakarta.

\section{Metode}

Jenis penelitian ini menggunakan pendekatan penelitian kualitatif. Objek penelitiannya adalah penguatan literasi budaya dan kewargaan kepada siswa berbasis sekolah. Penelitian mengambil lokasi di sebuah Sekolah Menengah Pertama Swasta di Kota Yogyakarta. Subjek pada penelitian adalah Kepala Sekolah, Guru, petugas Perpustakaan, Siswa dan Orang Tua Siswa. Teknik pengumpulan data yang digunakan metode observasi, wawancara dan dokumentasi. Analisis data ditempuh dengan melakukan reduksi data, penyajian data dan penarikan kesimpulan.

\section{Hasil dan Pembahasan}

Hasil penelitian menunjukkan bahwa penguatan literasi budaya dan kewargaan kepada siswa berbasis literasi di sekolah SMP sampel di Yogyakarta mampu memahamkan siswa. Gerakan literasi budaya dan kewargaan di sekolah berupa pelaksanaan pembiasaan membaca 15 menit sebelum pembelajaran dimulai, interaksi antara petugas perpustakaan dengan siswa, penanaman nilai-nilai karakter yang di antaranya adalah nilai karakter disiplin, kreatif, rasa ingin tahu, menghargai prestasi, 
mencintai budaya sendiri, gemar membaca dan tanggung jawab. Selebihnya, dalam rangka penguatan literasi budaya dan kewargaan pada siswa terdapat pengembangan fasilitas literasi sekolah serta tingkat keterlibatan pelaku atau tim fasilitator.

\section{Pembiasaan Membaca 15 Menit Sebelum Pembelajaran Dimulai}

Gerakan literasi sekolah khususnya literasi budaya dan kewargaan sangat diperlukan dalam dunia pendidikan salah satunya penguatan litersi budaya dan kewargaan kepada siswa. Dalam tahapan pembiasaan sekolah memprogramkan literasi budaya dengan kegiatan. Pembiasaan membaca 15 menit sebelum pembelajaran dimulai serta memiliki tujuan yaitu untuk meningkatkan minat baca siswa dan meningkatkan keterampilan membaca agar pengetahuan dapat dikuasai dengan baik oleh siswa (Safitri et al., 2019). Dalam rangka penguatan literasi budaya dan kewargaan, siswa dituntut untuk melaksanakan kegiatan membaca dan menulis yang berkaitan dengan bahan bacaan tentang kebudayaan dan kewargaan selama 15 menit sebelum pembelajaran dimulai setiap hari Senin, dilaksanakan dalam sebulan dua kali.

\section{Kegiatan Pengembangan Kemampuan Literasi Melalui Kegiatan di Perpustakaan}

Tahap pengembangan kemampuan literasi melalui kegiatan di perpustakaan diperlukan dalam kegiatan literasi sekolah guna untuk meningkatkan kemampuan literasi siswa. Salah satu cara meningkatkan kemampuan literasi bagi siswa melalui kegiatan di perpustakaan di antaranya adalah kegiatan membaca dan menulis, kegiatan mencari sumber belajar serta menanggapi bacaan pengayaan (Setiawan \& Sudigdo, 2019). Hasil penelitian mengungkap bahwa kegiatan pengembangan kemampuan literasi di perpustakaan SMP sampel bahwa siswa di tuntut untuk melaksanakan kegiatan membaca dan menulis, bahan buku bacaan yang digunakan untuk kegiatan membaca dan menulis di perpustakaan adalah bahan buku yang bertemakan kebudayaan dan kewargaan seperti buku sejarah, atlas, buku tentang ras, agama dan kebudayaan di Indonesia selain itu siswa di wajibkan untuk meminjam buku bertemakan budaya dan kewargaan disekolah. Kegiatan pengembangan kemampuan literasi budaya dan kewargaan di perpustakaan yang lain adalah kegiatan mencari sumber belajar di perpustakaan khususnya sumber belajar yang bertema kebudayaan dan kewargaan.

\section{Kegiatan Pelaksanaan Pembelajaran Berbasis Literasi Melalui Membaca Buku Nonteks}

Buku merupakan salah satu sumber utama ilmu pengetahuan dan teknologi. Buku-buku non teks pelajaran yang melekat dalam kegiatan pembelajaran merupakan media efektif untuk memperkaya pengetahuan peserta didik sesuai dengan ciri khas dan kondisi, termasuk minat dan kegemaran peserta didik. Hasil menunjukkan bahwa dalam kegiatan pelaksanaan kegiatan literasi budaya dan kewargaan pada tahap pembelajaran siswa diarahkan untuk membaca buku pengayaan dan buku referensi agar siswa tidak merasakan bosan dengan bahan bacaan setiap hari dalam melakukan kegiatan literasi.

\section{Penanaman Nilai Karakter}

Keterampilan kegiatan literasi budaya dan kewargaan tidak terlepas dari dukungan pembentukan maupun penanaman dari kualitas karakter seseorang terutama siswa. Pembentukan kualitas karakter siswa dapat dilakukan dalam kegiatan Gerakan Literasi Sekolah (GLS, penanaman nilai karakter siswa melalui gerakan literasi sekolah merupakan proses humanisasi pendidikan (Wisudayanti, 2020) dan upaya menumbuh kembangkan budi pekerti pada siswa di sekolah sehingga menjadikan pembelajar sepanjang hayat yang berkarakter baik (Teguh, 2020). Dari data penelitian peneliti menemukan bahwa salah satu penanaman nilai karakter yang dilakukan di sekolah dalam rangka kegiatan literasi budaya dan kewargaan yaitu dengan cara penanaman atau penguatan nilai karakter disiplin, kreatif, rasa ingin tahu, menghargai prestasi, cinta tanah budaya sendiri, gemar membaca dan tanggung jawab.

\section{Tingkat Keterlibatan Pelaku atau Fasilitator Sekolah Dalam Rangka Penguatan Literasi Budaya dan Kewargaan}

Kepala sekolah sebagai pemimpin dan pada saat yang sama pemegang kebijakan harus memiliki strategi yang tepat. Ini adalah pekerjaan rumah yang bagus untuk semua lembaga pendidikan di Indonesia. Hasil penelitian menunjukkan bahwa strategi kepala sekolah dalam 
meningkatkan literasi budaya dan kewargaan adalah pertama, pelaksanaan kegiatan literasi. Kedua, literasi siswa diarahkan pada keterampilan kegiatan literasi. Ketiga, membentuk tim literasi. Ini belum dikatakan maksimal karena sekolah memiliki kendala yaitu kendala fasilitas sekolah seperti fasilitas kelas, ruang perpustakaan dan fasilitas sarana dan prasarana.

Peran guru dalam mengimplementasikan gerakan literasi budaya dan kewargaan dianggap sangatlah penting, mengingat guru adalah orang yang menjalankan proses belajar mengajar. Ujung tombak kegiatan pembelajaran ada di pundak guru. Kebijakan apa pun yang dibuat pemerintah pusat, guru tetaplah senjata utama merealisasikan kebijakan tersebut. Peneliti juga menemukan bahwa sejauh ini para tenaga pendidik di sekolah SMP sampel di Yogyakarta dalam melakukan perencanaan hanya berbentuk RPP yang hanya berisi tentang rencana mengejar secara menyeluruh tidak semua secara khusus di rancang untuk kegiatan literasi budaya dan kewargaan. Ditemukan bahwa hampir setiap guru belum melakukan perencanaan yang secara khusus di rancang untuk kegiatan literasi budaya dan kewargaan.

Untuk menjadi sekolah yang berkualitas, tentu sekolah itu memiliki bermacam program, demikian pula SMP sampel di Yogyakarta. Berdasarkan data wawancara yang di peroleh dari peneliti salah satu program literasi budaya dan kewargaan dan juga program perpustakaan sekolah yaitu meningkatkan minat membaca siswa terhadap buku-buku budaya, baik itu buku pelajaran ataupun buku-buku bacaan lain seperti komik, cerpen, buku sejarah, dan bahkan novel. Petugas perpustakaan membuat program kunjungan wajib ke perpustakaan bagi siswa kelas satu sampai kelas 3 SMP sampel di Yogyakarta, program ini berupa jadwal kunjungan ke perpustakaan yang sudah dikoordinasikan dengan guru kelas yang wajib diikuti oleh seluruh siswa.

Kebutuhan akan literasi tidak dapat dipisahkan dari dunia pendidikan. Literasi menjadi wahana bagi peserta didik untuk mengenal, memahami, dan menerapkan ilmu yang mereka dapatkan. Literasi juga menjadi suatu pembiasaan bagi peserta didik baik di rumah maupun di lingkungan sekolah. Dengan demikian, literasi menjadi suatu komponen penting bagi keberhasilan peserta didik untuk mencapai hasil belajar yang ingin dicapai. Dari hasil pengamatan bahwa peran siswa dalam ragka penguatan kegiatan literasi budaya dan kewargaan yaitu menumbuhkan kegiatan minat baca dan partisipasi siswa dalam mengunjungi perpustakaan selain siswa menumbuhkan minat baca dan menanamkan nilai-nilai karakter yang di bentuk oleh pihak sekolah.

\section{Simpulan}

Hasil penelitian menunjukkan adanya kesimpulan bahwa penguatan literasi budaya dan kewargaan kepada siswa berbasis literasi di sekolah sampel di Yogyakarta meliputi: (1) Pelaksanaan pembiasaan membaca 15 menit sebelum pembelajaran dimulai, bahan bacaan yang digunakan adalah bahan bacaan yang bertema tentang kebudayaan, buku sosial, buku sejarah dan pendidikan kewarganegaraan; (2) Pengembangan kemampuan literasi budaya melalui kegiatan di perpustakaan yaitu kegiatan membaca dan menulis buku kebudayaan dan buku sejarah, serta mencari sumber belajar di perpustakaan bertemakan kebudayaan, pelaksanaan kegiatan menonton video tentang sejarah dan kebudayaan-kebudayaan yang ada di Indonesia; (3) Menanamkan nilai-nilai karakter yang di antaranya adalah nilai karakter disiplin, kreatif, rasa ingin tahu, menghargai prestasi, mencintai budaya sendiri, gemar membaca dan tanggung jawab; (4) Pengembangan fasilitas literasi sekolah. Sekolah sudah merancang untuk penambahan ruang kelas, peluasan ruang perpustakaan dan perancangan untuk pembuatan pojok baca di perpustakaan maupun di dalam kelas; (5) Peran guru selalu menyiapkan bahan ajar dan materi yang berhubungan langsung dengan penerapan literasi budaya dan kewargaan, menyampaikan nilai-nilai yang tergantung dalam pembelajaran sejarah serta mengajak siswa untuk mengunjungi perpustakaan, menyediakan bahan bacaan tentang kebudayaan dan sosial misalnya buku sejarah, gambar-gambar rumah adat, baju adat.

\section{Referensi}

Afifah, N. A., Erwina, W., \& Rohman, A. S. (2020). Peran Tenaga Perpustakaan dalam Mewujudkan Keberhasilan Gerakan Literasi Sekolah (GLS) di SD Negeri 02 Rajamandala. Jurnal Pustaka Budaya, 7(2), 105-112.

Desyandri, D. (2018). Nilai-Nilai Kearifan Lokal untuk Menumbuhkembangkan Literasi Budaya di Sekolah Dasar. Sekolah Dasar: Kajian Teori Dan Praktik Pendidikan, 27(1), 1-9. 
Fauziyah, N. (2019). Fundraising Taman Bacaan Masyarakat (TBM): Tinjauan terhadap Strategi Akuisisi Bahan Bacaan di TBM Teras Baca Guyub Rukun. Nusantara Journal of Information and Library Studies (N-JILS), 2(1), 1-10.

Frans, T. (2017). Pembelajaran Bahasa Dan Sastra Sebagai Penguatan Dan Pemertahanan Nilai-Nilai Lokal. JURNAL TAHURI, 14(2), 8-19.

Maimun, M., Sanusi, S., Rusli, Y., \& Muthia, H. (2020). Internalisasi Nilai-nilai Karakter Kebangsaan Melalui Literasi Budaya dan Kewarganegaraan di Sekolah Menengah Atas (SMA) Kota Banda Aceh. CIVICUS: Pendidikan-Penelitian-Pengabdian Pendidikan Pancasila dan Kewarganegaraan, 8(1), 8-15.

Nahdi, K., \& Yunitasari, D. (2019). Literasi Berbahasa Indonesia Usia Prasekolah Ancangan Metode Dia Tampan dalam Membaca Permulaan. Jumal Obsesi: Jumal Pendidikan Anak Usia Dini, 4(1), 446-453.

Pratiwi, A., \& Asyarotin, E. N. K. (2019). Implementasi literasi budaya dan kewargaan sebagai solusi disinformasi pada generasi millennial di Indonesia. Jurnal Kajian Informasi \& Perpustakaan, 7(1), 65-80.

Safitri, L., Muslim, A. H., \& Hawanti, S. (2019). Pengaruh membaca 15 menit terhadap minat baca siswa Sekolah Dasar. Jurnal cakrawala pendas, 5(2).

Setiawan, A. A., \& Sudigdo, A. (2019). Penguatan Literasi Siswa Sekolah Dasar melalui Kunjungan Perpustakaan. In Prosiding Seminar Nasional PGSD (pp. 24-30).

Teguh, M. (2020). Gerakan literasi sekolah dasar. Jurnal Pendidikan Dasar Flobamorata, 1(2), 1-9.

Widayoko, A., \& Muhardjito, M. (2018). Analisis Program Implementasi Gerakan Literasi Sekolah (Gls) Dengan Pendekatan Goal-Based Evaluation. Jurnal Tatsqif, 16(1), 78-92.

Wisudayanti, K. A. (2020). Pengembangan Kecerdasan Emosional Siswa di Sekolah Dasar Melalui Penanaman Pendidikan Karakter. Edukasi: Jurnal Pendidikan Dasar, 1(2), 135-146.

Yusuf, R., \& Putra, I. (2019, October). Pelaksanaan Literasi Kewarganegaraan Di Sekolah Menengah Atas Kota Banda Aceh. In Prosiding Seminar Nasional "Reaktualisasi Konsep Kewarganegaraan Indonesia" (Vol. 1, pp. 143-150). Fakultas Ilmu Sosial Universitas Negeri Medan.

Zakirman, Z. (2019). Peningkatan Minat Baca Siswa Melalui Penerapan Model Pembelajaran PlayThink-Pair-Share Di SDN 19 Nan Sabaris. Shaut Al-Maktabah: Jurnal Perpustakaan, Arsip Dan Dokumentasi, 11(1), 41-51. 